\title{
Research on the Efficiency Evaluation of Rural Space Governance Methods from the Perspective of Flow Theory
}

\author{
Qianting Chen, Chongqing University, CHINA \\ Yanzhu Ding, Chongqing University, CHINA \\ LI Yang, Chongqing University, CHINA \\ Chao Li, Beijing Dianju Information Technology Co., Ltd, CHINA \\ Jian Tang, Chongqing Design Institute Co., CHINA
}

\begin{abstract}
Chinese rural spatial governance has uneven application effects, and the existing efficiency evaluation methods lack dynamic and universal applicability. Therefore, this paper builds an evaluation system of rural spatial governance based on the essential purpose of rural spatial governance--promoting the flow of urban and rural elements.. Firstly, the result uses the urban-rural interaction behavior to correlate flow theory and governance behavior function logicas the technical basis of this paper.Second, the comprehensive analysis of existing studies on the evaluation index of empowerment results to determine the coefficient of evaluation index. $A$ complex network model was constructed to quantify the flow behavior of index elements as the primary data for comparative analysis. Finally, Xizhou specialty town was selected as the experimental object to verify the application of the evaluation system proposed in this paper. It is found that the governance behavior of specialty towns has a significant promoting effect in Xizhou, but the influence is not sustainable. It is mainly manifested in the obvious improvement of population factor flow; The flow of capital and technological factors presents the trend of grouping and de-grouping, respectively. The flow capacity of information elements is declining. On the analysis results, relevant suggestions are put forward to adjust the flow behavior in order to use the quantifiable evaluation system established in this paper to provide a new perspective and path for the development and construction of China's rural revitalization period.
\end{abstract}

\section{Keywords}

urban-rural relations, rural space governance, efficiency evaluation system, flow theory, complex network analysis

\section{Introduction}

Some scholars took the major policy adjustment and phased goals of rural governance as the analysis basis, and divided China's rural governance into six different stages ${ }^{[1]}$, so now rural governance is in the period of the rural revitalization strategy. The implementation of the rural revitalization strategy aims to stimulate the endogenous driving force of rural development and reshape the harmonious urban-rural relations ${ }^{[2]}$. The country and local actively put forward the action strategy to promote rural development, beautiful rural construction, rural complex construction, specialty town construction with significant social benefits to promote the flow between urban and rural factors change ${ }^{[3]}$. They have accelerated the profound transformation of China's urban-rural relations and pushed them into a new stage of truly 
integrated development.

In order to ensure the rationality and effectiveness of rural spatial governance methods, scholars from all walks of life have carried out a large number of related studies to evaluate the effect of rural governance.In terms of evaluation basis, the following two related evaluation types are mainly used.One is the sustainable development of related society, which is the long-term requirements and objectives of social development ${ }^{[4][5][6],}$ thus determines whether the governance method effectively responds to the long-term concern of urban and rural construction, and the other is the connotation of related governance ${ }^{[7][8][9]}$, thus judging whether the governance method meets the evaluation method and technology are more targeted.These two types of evaluation studies are highly operational for explicit associated subjects, but they are still insufficient in identifying governance methods at a deeper and macro level of urban-rural relations.

In essence, the urban-rural relationship is not only the basis of urban-rural interaction, but also the result of urban-rural interaction. The flow of population, land, capital, information, technology, ecology and other elements that run through the whole process of urban and rural interaction is the core of building a benign relationship between integrated urban and rural development. The application of "flow" theory can provide a path to identify the characteristics, pattern and effect of factor flow ${ }^{[10]}$, which provides a theoretical basis and method path for the evaluation of rural governance methods to promote the evolution of urban and rural relations.

\section{The Logical Construction of Rural Space Governance in Flow Theory}

Rural spatial governance serves as a collection of spatial intervention means to promote the improvement of urban and rural relations, and flow space theory can be used as a basis to describe and explain the flow phenomenon of urban and rural factors. It cannot directly realize connotation correspondence and mutual conversion between the two.However, the urban-rural relationship, as the common object of the two applications, provides a touch point for the connection between the two.Therefore, this paper first uses the link of urban-rural relationship between rural governance and flow space theory to transform the connotation of the two, so as to build the interpretation framework of rural spatial governance behavior under flow space theory, and build a theoretical basis for the quantification of rural governance efficiency.

\subsection{Urban-rural interaction from the perspective of flow space}

The concept of flow space is proposed by Castells, which is defined as "social practice organization sharing time by the material flow between cities without adjacent geographical location". Its overall structure includes four aspects: flow element, flow carrier, flow node and flow control system.Correspondingly, in the context of urban and rural factor flow, Adams believed that factor flow is the inflow of related factors of production, thus forming the professional division of labor in different regions ${ }^{[11]}$. Marx believed that the flow, especially the flow of labor force, is the core variable that determines the development status of different industries and regions ${ }^{[12]}$.At the same time, with the enhancement of urban and rural economic and social and spatial connection, scholars re-examined the urban-rural relations from the perspective of urban-rural interaction.Princeton proposed the concept of urban-rural interaction to describe the close connection and interdependent relationship between urban and rural areas, and summarized it into five types of flow, population flow, commodity flow, capital flow, social transaction, and administrative service supply ${ }^{[13]}$. Tacoli believes that urban-rural relations include the flow of people, goods, capital and other social trading practices ${ }^{[14]}$. At the same time, Chinese scholars describe the development and evolution of urban-rural relations by demonstrating the interaction between economy, society, nature and ecological subsystems ${ }^{[15]}$.On the whole, the internal mechanism of the evolution of urban-rural relations is the stage of economic development, and is externalized into 
the change of the direction and quantity of urban and rural factors flow ${ }^{[16]}$. The dominant system of vector flow, flow carrier, flow node and flow elements jointly describe the dynamic spatial structure of urban and rural element transmission ${ }^{[17]}$.Therefore, the factor flow between urban and rural areas provides the identification scene for the connotation of flow theory and the identification of urban-rural relations, and also clarifies the operation object for the guidance of the quantification of rural governance efficiency, that is, namely the form of urban-rural interaction.To sum up, in this paper, population, capital, technology and information are selected as four ways to carry the urban-rural interaction (Table 1).

Table 1 Interpretation of urban and rural interaction behavior under flow space theory

\begin{tabular}{|c|c|c|c|}
\hline $\begin{array}{l}\text { Form of urban and rural } \\
\text { interaction-flow elements }\end{array}$ & Main flow carrier form & Flow node & Flow control system \\
\hline Population & $\begin{array}{l}\text { People themselves, } \\
\text { enterprises, etc }\end{array}$ & \multirow{4}{*}{$\begin{array}{l}\text { Cities } \\
\text { Country }\end{array}$} & \multirow{4}{*}{$\begin{array}{l}\text { Relevant documents, administrative } \\
\text { means for local and state guidance to } \\
\text { optimize urban and rural factors in the } \\
\text { form, or systems and paths to realize }\end{array}$} \\
\hline Funding & $\begin{array}{l}\text { Capital trading behavior } \\
\text { of enterprises, banks, } \\
\text { individuals, etc }\end{array}$ & & \\
\hline Technology & $\begin{array}{l}\text { Enterprise cooperation, } \\
\text { Technical support } \\
\text { behavior, etc }\end{array}$ & & \\
\hline Information & Internet, TV, etc & & \\
\hline
\end{tabular}

\subsection{Application mechanism of rural governance in urban-rural relations}

Rural spatial governance not only responds to the practical needs of material space improvement in rural areas, but also governs all kinds of external relations carried by material space, creating conditions for deepening the rural governance system to promote the integration of urban and rural development. In order to understand the role and effect of rural governance methods, some scholars directly discuss the influence of governance methods on urban and rural relations through sorting out the phased themes of rural governance, which is difficult to distinguish the mechanism of action, Because there is a lack of a for " any policy, Its functions are all realized through the detailed characterization of the objective behavior produced by the dynamic form of the mutual connection between things ${ }^{[18]}$ ".On the whole, the study of rural governance methods and rural governance methods inevitably involves the description of the free flow of population, material, capital and other factors between urban and rural areas ${ }^{[19][20][21]}$. This is because the rural space governance in urban and rural relations, the main "dynamic form" can be identified, but it is difficult to be completely listed, so according to the above in the summary of urbanrural relationship interaction scene determine four main forms of urban-rural interaction type, namely as rural space governance "dynamic form", thus for the late efficiency identification clear quantitative object.

In order to explain the form of rural governance more carefully into the urban and rural interaction scene, according to the definition ${ }^{[22]}$ of rural governance and the existing research and summary of rural 
governance behavior ${ }^{[23]}$, the connotation of rural governance behavior includes: governance subject, governance object, governance logic, governance purpose and process and performance.(Table 2):

Table 2 Expression of rural spatial governance in urban and rural relations

\begin{tabular}{|c|c|c|c|c|c|}
\hline $\begin{array}{c}\text { Governance } \\
\text { subjects }\end{array}$ & $\begin{array}{l}\text { Dynamic form of } \\
\text { governance } \\
\text { object-urban and } \\
\text { rural action }\end{array}$ & $\begin{array}{c}\text { Governance } \\
\text { logic }\end{array}$ & $\begin{array}{c}\text { Governance } \\
\text { purposes }\end{array}$ & $\begin{array}{c}\text { Governance } \\
\text { process }\end{array}$ & $\begin{array}{l}\text { Governance } \\
\text { performance }\end{array}$ \\
\hline $\begin{array}{l}\text { Organizations or } \\
\text { individuals that } \\
\text { play a direct or } \\
\text { indirect dynamic } \\
\text { role in rural } \\
\text { spatial } \\
\text { governance } \\
\text { practices. }\end{array}$ & $\begin{array}{c}\text { Population } \\
\text { Funding } \\
\text { Technology } \\
\end{array}$ & $\begin{array}{r}\text { Defied spec } \\
n\end{array}$ & $\begin{array}{l}\text { cally according } \\
\text { nagement met }\end{array}$ & the specific & $\begin{array}{l}\text { In this paper, we } \\
\text { study the } \\
\text { objectives }\end{array}$ \\
\hline
\end{tabular}

\subsection{Construction of the Relationship between Rural Space Management Mode and Flow}

\section{Space Theory}

Flow theory describes the interaction between urban and rural population, capital, technology, ecology, that is, urban and rural relations, and later can use the Internet data, real-time monitoring data, statistical data, social investigation and other multiple source data to analyze and depict the characteristics and pattern of urban and rural factors flow and interaction, influencing factors and mechanism ${ }^{[10]}$. And rural space governance as a role and optimize the relationship between urban and rural areas, the evaluation of the development and progress of the theoretical assumptions in the empirical system can be observed, measure index, only with such index system, it is possible to achieve a comprehensive, systematic, objective analysis and evaluate the development and progress of rural space governance research goals ${ }^{[24]}$. Through the establishment of flow space between urban and rural relationship and rural space governance in urban and rural combing, thus can use urban-rural interaction relationship as a medium to flow space theory and rural space governance behavior, the rural space governance object for text application flow theory, including the flow of population, capital, technology and information, they are both flow elements and the object of rural space governance.

\section{The rural spatial governance efficiency evaluation system}

This paper from the essence of rural space governance and goal, based on the logical correlation between the flow space theory and rural space governance behavior, the population, capital, technology and information exchange activities as evaluation scene and dimension, while the evaluation index stability, 
the evaluation method feasibility and operability ${ }^{[25]}$.At the same time, determine the weight of the evaluation index comprehensively, and finally build the evaluation index system.

\subsection{The evaluation index}

Entering the information and post-industrial society, the attention to urban and regional space changes from production space to consumption space, emphasizing the importance of resident activity space. Therefore, resident mobility and behavioral activity space organization become the main content and form of flow space. Some scholars think that the driving force of labor flow is divided into macro and micro factors, China's macroeconomic strategy, household registration system, and micro individuals and their families face income, welfare, risk factors intertwined, work together ${ }^{[26]}$, and mainly manifested in regional economic growth ${ }^{[27]}$, housing $\operatorname{cost}^{[28]}$, industry and urban spatial organization structure ${ }^{[29]}$, etc; The agglomeration of capital elements in cities and cities depends on the scale, market, efficiency, talent and facility efficiency of the central city, It is on these advantages, Secondary and tertiary industries within the scope of urban radiation, Population and talent, Raw materials, funds, science and technology attract to central cities; Technical flow refers to the flow process of technical capabilities, it covers and goes beyond the meanings of technological innovation, technology transfer, technology transfer.Enterprises are the main body of technology flow, and the spatial mode of technology flow largely depends on the technical strategy of the enterprise, including the conditions, methods, timing and level of enterprise technology diffusion. The key node to the success of technology flow is technology acceptance enterprises ${ }^{[30]}$; Hall believes that the rapid and large flow of information through urban areas is an essential feature of post-industrial cities.Information flow reshapes the urban cyberspace to a certain extent.Therefore, a large number of network information flow data generated by the Internet, such as "Baidu Index ${ }^{[31] "}$ and "Internet flow rate ${ }^{[32] ", ~ c a n ~ b e ~ u s e d ~ a s ~ o n e ~ o f ~ t h e ~ i m p o r t a n t ~ m e a s u r e s ~ o f ~ t h e ~}$ research regional space, to characterize the urban networks, and as a useful and necessary supplement to the "entity" urban network research.

Summarize the expression of convective elements in urban and rural interaction transmission above and the way of concrete quantification of elements in existing research, and take into account the difficulty of forming data acquisition.This article uses the Dianping clock-in data, enterprise shareholder investment relationship, enterprise cooperation, local Baidu index search volume, to quantify the flow of people, capital flow, technology flow and information flow.

\subsection{Model construction and its evaluation method}

Social Network Analysis (SNA) focuses on "ties" data, studies the structural features existing in various "relationships" from a quantitative perspective, and performs social network analysis operations by importing data into software like Ucinet, Gephi, obtaining the topology of the network and performing feature analysis.This paper uses the construction of human, capital, technology and information flow model as the basis to measure the efficiency of spatial governance behavior.

\subsubsection{Construction of population element flow model and its evaluation method}

The model is constructed based on the real scene of crowd clocking recording. The data source is the crowd clocking information on the Dianping website. The complex network is determined by determining the relationship between the user attribution and the clocking point.The application area of governance means is the punch card point and the user belongs to the network node. The occurrence of clock card behavior is the side, and the empowerment is assigned to the number of punch cards. The model is built to identify the effect of attracting people after being treated, and to discuss whether the source of people has its own characteristics.For this purpose, the weighted network average is chosen to quantify this performance. 


\subsubsection{Construction of capital element flow model and its evaluation method}

The model is based on the real scene construction of "share mutual integration" among enterprises.The data source is determined through the share investment relationship between enterprises. The mobile network of cooperative behavior model based on legal person-shareholders involves personnel as the network node, and the share investment relationship between enterprises is the side of the network to reflect whether there is positive feedback on the quantity and stability of local industrial development under the intervention of governance means.To this end, the degree center potential is selected to evaluate the overall stability of the network structure, and modular indicators are used to evaluate whether there is a tight group structure in the network.Because the evaluation factor reflects the overall and local structure characteristics of the network, respectively, the analysis results of both factors are combined by 0.5 as the comprehensive evaluation result of this factor.

\subsubsection{Construction of Technical element Flow Model and Evaluation Method}

The model is constructed based on the cooperation behavior between enterprises in the governance area.The data source is consistent with the capital flow, the enterprise is set as the network node, and the network model is built based on the cooperative relationship behavior between enterprises, so as to evaluate whether the local enterprise cooperation mode intervened by governance means is stable and sustainable.To this end, the degree center potential is selected to quantify and evaluate the overall structural stability of the network, and to evaluate whether there is a tight group structure in the network with modular indicators. Because the evaluation factor reflects the overall and local structure characteristics of the network, respectively, the analysis results of both factors are combined by 0.5 as the comprehensive evaluation result of this factor.

\subsubsection{Construction of Information element Flow Model and its Evaluation Method}

The amount of search involved by governance means is the realistic basis for constructing the model.Set the towns and towns of the governance area and other domestic cities as the points, search behavior as the edge, and assign a complex network model with the value of the search quantity, so as to identify whether the information attention increases after the region is governance, and whether the source of search quantity has its own characteristics.For this purpose, the network weighted average is chosen to reflect and quantify this performance.

\subsection{The weight of the evaluation indicators}

In view of the comprehensive, authoritative and representative needs, the paper selected "SCl" source journal, "El" source journal, "CSSCI" and "CSCD" source journals for advanced retrieval as basic data sources.Due to the title of urban and rural relations in different periods, choose "keywords" = "urban and rural relationship evaluation + urban and rural development evaluation + urban and rural integration evaluation + urban and rural integration evaluation + urban and rural governance evaluation + urban construction evaluation ++ urban construction evaluation" * flow theory, accurate retrieval.In order to ensure the relevance of the retrieved documents, the search results were screened one by one, entries such as meeting solicitation, introduction, achievement introduction, book review and unrelated entries were deleted, and finally 114 documents were used as the basic data source for analysis(Table 3).

Table 3 Evaluation indicators and the weights 


\begin{tabular}{lll}
\hline Target layer & & Factor layer / space layer \\
\hline Indicator dimension & Indicator weight & Mass factor \\
\hline People & 0.35 & Dianping punch-in data \\
\hline Capital flow & 0.21 & Enterprise shareholder cooperation and contact \\
\hline Technical flow & 0.09 & Cooperative connection between enterprises \\
\hline Information flow & 0.44 & Baidu index search volume \\
\hline
\end{tabular}

\section{Verification and analysis of the evaluation methods}

\subsection{Subjects and Scope}

In order to identify the dynamic change process of urban and rural factors flow before and after governance intervention, this paper needs to better measure the change of urban and rural factors flow under the premise of a certain amount of data guarantee, and identify the promotion or inhibitory effect of control behavior. Xizhou intervened in its governance behavior earlier, which has considerable influence in the construction and development of national specialty towns, and the connection with cities is more diverse and complex. Therefore, the conclusions drawn using relevant methods will be more suitable for the objective situation.In order to ensure a certain amount of data to support this research work, the factor flow between Xizhou Town and other prefecture-level cities and county-level cities in the country is the research scope of this article.Through the annual quantification and analysis of each factor flow from 2014-2020, the respective change characteristics and overall changes of the flow of the four factors are obtained.

\subsection{Evaluation system verification results}

\subsubsection{People flow}

The weighted average rate of the flow of population elements has increased significantly since 2016, which reflects the obvious role of specialty town projects in promoting the consumption of migrants (affected by the epidemic in 2019, the weighted average growth rate has decreased, but still maintained a positive growth).

Table 4 Analysis of weighted average of Xizhou people

\begin{tabular}{|l|l|l|l|l|l|l|l|}
\hline Year & 2014 & 2015 & 2016 & 2017 & 2018 & 2019 & 2020 \\
\hline Weighted average & 2.571 & 3.25 & 5.143 & 8.24 & 12.056 & 24.928 & 34.541 \\
\hline Annual growth rate & -- & 0.26 & 0.58 & 0.60 & 0.46 & 1.07 & 0.39 \\
\hline
\end{tabular}

\subsubsection{Capital flow}

Comprehensive modular index and degree center potential data analysis, found that the network module degree index rising, in the network analysis is the cluster form, at the same time the degree center potential is declining, the absolute power relative to the last year, namely, the ability to interfere with the market and local stability is scattered, and the overall comprehensive performance improved significantly.In the stage of the outbreak of local tourism, field tourism economy is difficult to effectively 
support local development, should be on the basis of improving characteristic industry development, at the same time to introduce and encourage various types of related industries for its service support, such as handicraft industry, digital economy to cope with the possibility of damaged real economy, in effectively improve the enthusiasm of tourism service construction at the same time, increase the local industry development overall risk resistance ability.

Table 5 Evaluation of related indicators of Xizhou capital flow

\begin{tabular}{|l|l|l|l|l|l|l|l|}
\hline Year & 2014 & 2015 & 2016 & 2017 & 2018 & 2019 & 2020 \\
\hline Modular index & 0.844 & 0.853 & 0.886 & 0.91 & 0.919 & 0.923 & 0.928 \\
\hline Degree center potential & 0.1133 & 0.103 & 0.0827 & 0.0691 & 0.063 & 0.0596 & 0.0551 \\
\hline Comprehensive evaluation & 0.47865 & 0.478 & 0.48435 & 0.48955 & 0.491 & 0.4913 & 0.49155 \\
\hline
\end{tabular}

\subsubsection{Technical flow}

The Modular index suddenly rose and peaked in 2016, but since then the index has declined year by year and recovered in 2020.The performance of this index can be explained as saying that the enterprise cooperative operation mode is not well used in Xizhou. Even if the number of local enterprises increases year by year, a stable enterprise structure and production chain are difficult to form, and the local support industries are difficult to operate comprehensively.And the degree center potential is constantly decreasing, which further proves the problem reflected by the modular index.In the later stage, we should explore and develop deeper and diversified cooperation models, promote the cooperative development of local small and basic industries, and deepen the industrial chain.

Table 6 Analysis of Xizhou technical flow

\begin{tabular}{|l|l|l|l|l|l|l|l|}
\hline Year & 2014 & 2015 & 2016 & 2017 & 2018 & 2019 & 2020 \\
\hline Modular index & 0.678 & 0.639 & 0.747 & 0.625 & 0.613 & 0.600 & 0.656 \\
\hline Degree center potential & 0.2904 & 0.2551 & 0.2202 & 0.3119 & 0.2993 & 0.1432 & 0.1408 \\
\hline Comprehensive evaluation & 0.4842 & 0.44705 & 0.4836 & 0.46845 & 0.45615 & 0.3716 & 0.3984 \\
\hline
\end{tabular}

\subsubsection{Information flow}

On the whole, the weighted average of "Xizhou" network was the highest in 2016, compared with being rated as a town with Chinese characteristics; the index the year before 2016 increased year by year, and after 2016, the index was lower compared with the evaluation.It can be considered that the governance behavior of specialty towns has an obvious effect on the level of information flow transmission, but it is not lasting, etc. The publicity work of local specialty towns still needs to be strengthened.

Table 7 Analysis of the weighted average degree of Xizhou information flow

\begin{tabular}{|l|l|l|l|l|l|l|l|}
\hline Year & 2014 & 2015 & 2016 & 2017 & 2018 & 2019 & 2020 \\
\hline Weighted average & 50.286 & 65.429 & 77.314 & 57.086 & 53.543 & 45.771 & 41.371 \\
\hline
\end{tabular}

Based on the above analysis results of the factor flow, it is found that the flow of technology and information factors of Xizhou specialty town has been declining, the flow of population factors has been continuously improved, and the capital flow has remained relatively stable. Specialty town governance as 
the main form of intervention in Xizhou development this years, the promotion of some elements or neglect link is obvious, to effectively promote local development efficiency,the information and technology transmission level of related industries need to deepen and promote fame.However, from the perspective of the overall evaluation results, since the Specialty town intervened in the local development, the overall factor transmission efficiency has performed the best in the town model intervention in these years. Although the development is good in the later period, the overall rise rate is not obvious.It shows that Specialty towns have a certain positive impact and role in accelerating the requirements of urban and rural integration and promoting the flow of urban and rural factors, but the effect is not sustainable.Therefore, it is necessary to optimize and adjust the development mode of the town combined with the inadequate development of individual factors. At the same time, the influence mechanism between the factor flow is constantly explored, and increase the overall efficiency of urban and rural factors through the deepening adjustment of some factors.

Table 8 Four-factor flow analysis results and their comprehensive evaluation

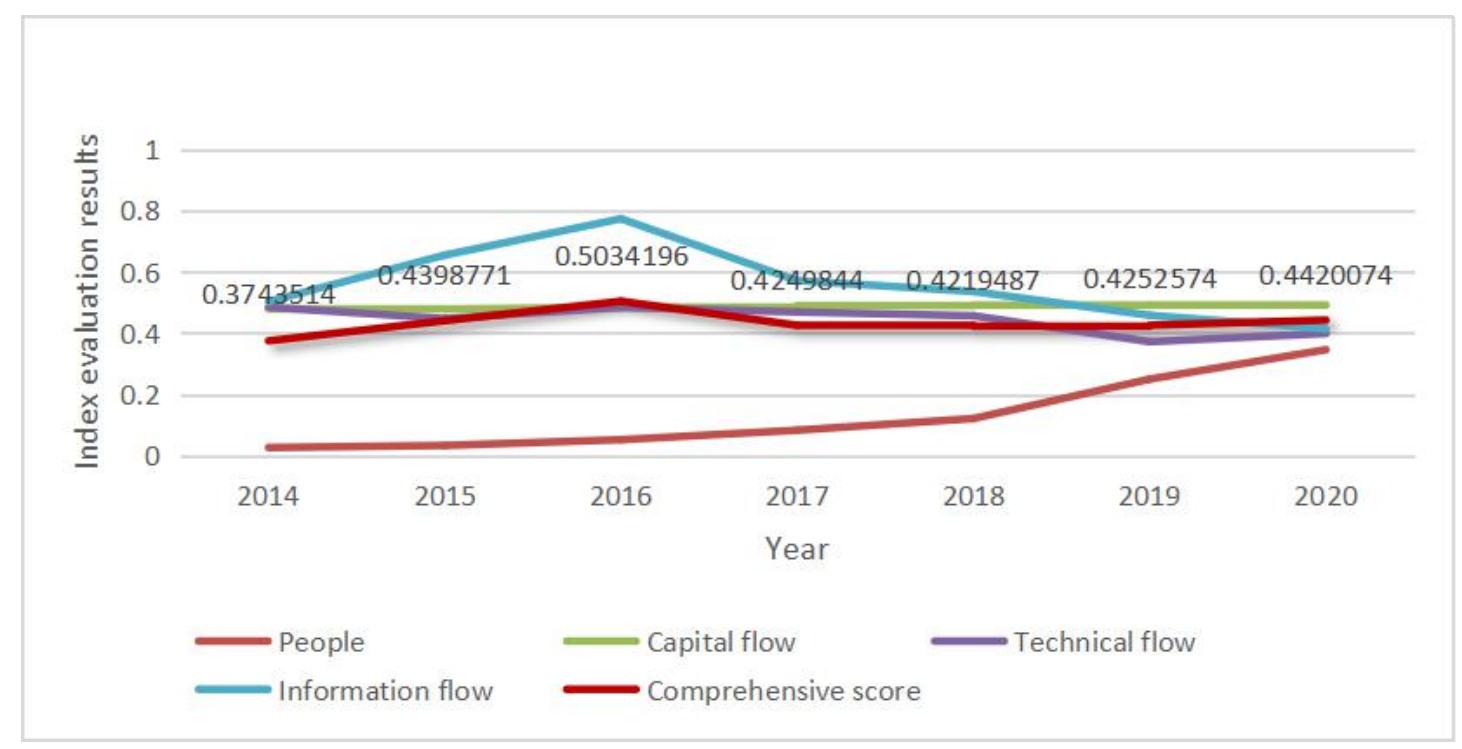

\section{Research discussion and deficiencies}

The main development goals of the current stage of Chinese rural construction and development is to boost the integration of urban and rural areas and synergize the flow of urban and rural factors. This study combines the quantitative description of the element flow behaviour in the perspective of the flow theory, an evaluation system to quantify the efficiency of rural governance means are thus generated. The method is deployed and verified by cases study, discovering that Xizhou as the object of the specialty town governance in the past seven years, the four main elements have shown their own characteristics. The overall flow of factors shows an obvious good development trend. But in the later stage, the industry chains of localities need to be strengthened continuously respectively, improving the overall resilience; Strengthen enterprise cooperation, cultivating industries and supporting industries to cope with the longterm impact on local tourism development due to the COVID pandemic; Promote the city image publicity by highlighting the local characteristics, so as to achieve local sustainable development goal.

This peril of demographic data used in this research is the credibility of the data collection platform., which could be mainly contributed to the insufficiency and incompetence of the reference factor flow. In the selecting process of the objects to quantify the flow of factors, the main forms of flow are stretched due to the loss of the interpretation of the main urban and rural factors and the difficulty of data collection. Although it is certainly partly representative but not overly competent. On the other hand, this 
paper is mainly to build up the spatial governance capacity efficiency evaluation system, however, only a sole case is verified by digging into its relevant problems already existed, an overall role strength of specialty towns, as a popular national governance behavior, cannot be reached respectively.

In any further study, the evaluation system needs to be respectively adjusted and optimized accordingly, mainly consistent with the local Chinese context, , enlarge the sample size of the evaluation cases, thus further discuss the contents and forms of factor flow under the Chinese special background to clarify the transmission mechanism between the development situation and the institutional pattern of governance. Therefore, it will be more effective to put forward political, societal and economical suggestions to boost the quality of Chinese rurality construction and the high-quality integration of urban and rural areas. 


\section{References}

[1] Ding, Z. G. and Wang, J. (2019). 70 Years: Historical Evolution and Logic Road. Rural China observation, (04), pp. 18-34.

[2] Ning, Z. Z. and Zhang, Q. (2020). The flow and optimal allocation of urban and rural factors under the background of rural priority development. Geographic studies, 39(10), pp. 2201-2213.

[3] Wang, Y. H. and Zhang, J. (2018). Development of county urbanization under the Rural Revitalization Strategy. Urban Development Research, 25(05), pp. 1-6.

[4] Luo, X. Y. (2017). Research on Rural Low Carbon Ecological Evaluation System Based on Carbon emission Accounting. Hangzhou: Zhejiang University.

[5] Sun, H. and Zhao, X. (2019). Quality Evaluation and Different Management Strategy of Rural Habitat Environment in China. Journal of Xi'an Jiaotong University (Social Science Edition), 39(05), pp. 105-113.

[6] Gu, X. K. Tao, S. Y. Lu, F. F. and Zhou, X. P. (2019). Takes the 89 of country towns in Shanghai as an example. Journal of Natural Resources, 34(11), pp. 2281-2290.

[7] Min, Z. R. Zhou, Y. and Zhang, Q. Y. (2018). Construction Evaluation System in Jiangxi Province. Planner, 34(11), pp. 138-141.

[8] Yang, B. Wang, Z. Yao, X. and Chai, J. (2020). Assessing the performance of land consolidation projects in different modes: A case study in Jianghan Plain of Hubei Province, China. International journal of environmental research and public health, 17(4), p. 1410.

[9] He, C. J. and Li, X. Q. (2016). Silver Yuan.Construction and application of the coupling degree evaluation index system of leisure agriculture and beautiful countryside. Regional Research and Development, 35(05), pp. 158-162.

[10] Liu, C. F. and Zhang, Z. Y. (2018). From urban-rural integration to urban-rural integration: thinking on new urban-rural relations. Geography Science, 38(10), pp. 1624-1633.

[11] Adam, S. (1972). Study of the nature and causes of national wealth. The Commercial Press.

[12] Marx. (2009). Das Kapital (All 3 volumes). Shanghai Sanlian Publishing House.

[13] Preston D. (1975). Rural-urban and inter-settlement interaction: Theory and analytical structure. Area, 7(3), pp. 171-174.

[14] Tacoli, C. (1998). Rural-urban interactions: a guide to the literature. Environment and urbanization, 10(1), pp. 147-166.

[15] Long, H. and Tu, S. (2018). Theoretical cognition of rural reconstruction. Advances in Geographical Sciences. Prog. Geogr, 37, pp. 581-590.

[16] Chang, Y. (2015). Study on the Influence of Element Flow on the Integration of Urban and Rural Development. Northwestern University.

[17] Zhu, Y. Y. Zeng, J. X. Han, Y. and Luo, X. (2016). Theoretical construction of spatial and temporal integration of urban and rural cultural information flow. Geography Science, 36(03), pp. 342-351.

[18] Ma, R. J. Wang, R. K. and Zuo, X. M. (2013). Principles of Management. People's Post and

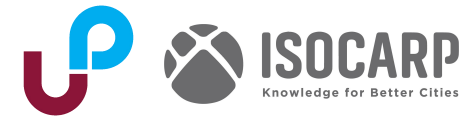


Telecommunications Press.

[19] Geng, G. W. and Wang, Y. Q. (2019). Logic of the evolution of Rural Governance from the perspective of Urban-Rural Relations: 1949 2019. Rural China Observation, (06), pp. 19-31.

[20] Feng, D. J. and Wang, C. L. (2014). A Study on Chinese Differential Urban-Rural Integration under the Framework of Public Finance. Journal of Zhongnan University of Economics and Law, (05), pp. 46-50.

[21] Zou, L. L. Li, Y. R. Liu, Y. S. and Wang, J. Y. (2021). Functional Theory Construction and Positive Study of farmland "Three Students" from the perspective of elements. Geography Research, 40(03), pp. 839855.

[22] Yang, B. (2019). Research on CPC Rural Governance in the New Era. Southwestern Jiaotong University.

[23] Hu, J. H. (2014). Rural democratic management system: legal analysis and legal guarantee. Central China Normal University.

[24] Guo, Z. L. (2004). Rural Governance and its Institutional Performance Evaluation: Study and Rational Case Analysis. Proceedings of Central China Normal University (Humanities and Social Sciences), (04), pp. 24-31.

[25] Gu, X. K. Tao, S. Y. Lu, F. F. and Zhou, X. P. (2019). Takes the 89 of country towns in Shanghai as an example. Journal of Natural Resources, 34(11), pp. 2281-2290.

[26] Zhao, F. (2015). Star Xiaochuan, Li Huijuan.Review on urban and rural labor flow: Theory and Chinese Empirical. China Population Resources and Environment, 25(04), pp. 163-170.

[27] Zhang, L. (2013). Flement flow, industrial transfer and regional economic development. Huazhong University of Science and Technology.

[28] Zhang, H. F. Zhang, J. R. and Yao, X. G. (2019). The spatial evolution of housing cost and the decision influence of labor flow in China. Economic Geography, 39(07), pp. 31-38.

[29] Zhao, N. (2016). The Spatial Effect of Labour Flow and Industrial Structure Adjustment. Statistical Study, 33(02), pp. 68-74.

[30] Xu, X. Q. Wang, X. and Yan, X. P. (2002). Dynamic mechanism, channel and mode of technical flow - takes the Pearl River Delta for example. Geography, (04), pp. 489-496.

[31] Wang, Q. X. Zhang, X. S. Cheng, Y. (2018). The spatial Organization of Yangtze River Delta Urban Agglomeration from the View of Information Flow - - Urban Network Analysis Based on Baidu Index. Journal of Urban Planning, (03), pp. 105-112.

[32] Wang, N. N. Chen, R. and Zhao, Y. (2016). Internet Information Space Network Analysis Based on Information Flow. Geographic study, 35(01), pp. 137-147. 